\title{
Loss of androgen receptor expression predicts early recurrence in triple-negative and basal-like breast cancer
}

Aye Aye Thike 1,2,3,4, Luke Yong-Zheng Chong ${ }^{1,2,3,4}$, Poh Yian Cheok ${ }^{2}$, Hui Hua $\mathrm{Li}^{3}$, George Wai-Cheong Yip ${ }^{3}$, Boon Huat Bay ${ }^{4}$, Gary Man-Kit Tse ${ }^{1,2,3,4}$, Jabed Iqbal ${ }^{1,2,3,4}$ and Puay Hoon Tan ${ }^{1,2,3,4}$

${ }^{1}$ Department of Pathology, Singapore General Hospital, Singapore, Singapore; ${ }^{2}$ Department of Clinical Research, Singapore General Hospital, Singapore, Singapore; ${ }^{3}$ Department of Anatomy, Yong Loo Lin School of Medicine, National University of Singapore, Singapore, Singapore and ${ }^{4}$ Department of Anatomical and Cellular Pathology, Chinese University of Hong Kong, Hong Kong, China

Treatment of triple-negative invasive breast cancers, defined by the absence of estrogen and progesterone receptors and c-erbB2 expression, remains challenging. Androgen receptor, a member of the nuclear receptor superfamily that is involved in signaling pathways regulating cell proliferation, has been implicated in breast tumorigenesis. We immunohistochemically examined the expression of androgen receptor, basal markers (CK14, 34ßE12) and EGFR in 699 triple-negative invasive breast cancers in tissue microarrays using the streptavidin-biotin method, and correlated the findings with clinical outcome. Positive androgen receptor expression was defined as staining of $1 \%$ or more of tumor cell nuclei. Survival outcomes were estimated with the Kaplan-Meier method and compared between groups with log-rank statistics. Cox proportional hazards models were used to determine the effect of androgen receptor on survival outcomes. Immunohistochemical positivity was observed in $38 \%$ of tumors, with the proportion of stained tumor cells ranging from 1 to $95 \%$ (mean $29 \%$, median 10\%). Androgen receptor expression was inversely associated with histologic grade and mitotic score. CK14, 34/E12 and EGFR confirmed $85 \%$ of cases to be basal-like, without significant association of basal-like phenotype with androgen receptor expression. Disease-free survival was significantly better in androgen receptor-positive triple-negative breast cancer, with a trend for improved overall survival. Decreased recurrence likelihood in both triple-negative and basal-like tumors (hazard ratio, 0.704 ; $95 \%$ confidence intervals, 0.498-0.994; $P=0.0464$; and hazard ratio, $0.675 ; 95 \%$ confidence intervals, $0.468-0.974 ; P=0.0355$, respectively) was noted within 5 years of diagnosis but not thereafter. Our study suggests that loss of androgen receptor in triple-negative breast cancers augurs a worse prognosis, including those with basal-like features. More work in elucidating its relationship with mechanisms of progression, as well as trials of targeted treatment for androgen receptor-expressing triple-negative tumors, needs to be performed.

Modern Pathology (2014) 27, 352-360; doi:10.1038/modpathol.2013.145; published online 9 August 2013

Keywords: androgen receptor; outcome; triple-negative and basal-like breast cancer

Triple-negative breast cancer is defined by a lack of expression of both estrogen and progesterone receptors (ER, PR), as well as the human epidermal growth factor receptor (HER2/cerbB2). It is characterized by distinct molecular, histological and clinical features including a particularly

Correspondence: Dr PH Tan, FRCPA, Department of Pathology, Singapore General Hospital, 20 College Road, Academia, Level 7, Diagnostics Tower, Singapore 169856, Singapore.

E-mail: tan.puay.hoon@sgh.com.sg

Received 9 May 2013; revised 20 June 2013; accepted 21 June 2013; published online 9 August 2013 unfavorable prognosis, ${ }^{1-3}$ despite increased sensitivity to standard cytotoxic chemotherapy regimens. ${ }^{4,5}$ Numerous efforts are currently being undertaken to improve prognosis for patients with triple-negative breast cancer. Targeted treatment of triple-negative breast cancers remains challenging, yet is indeed promising. A number of molecular targets have been identified that are currently under investigation for managing this entity. ${ }^{6-8}$

The role of hormone receptors as prognostic and therapeutic tools has widespread acceptance in the management of breast cancer. Recently, it has been suggested that androgen receptor has an emerging 
role in patients with breast cancer, especially ER-negative tumors. ${ }^{9-11}$ Although ER is widely recognized for its role in breast cancer, little is known about the potential role of androgen receptor in this disease. Steroid hormone receptors are crucial components of signaling pathways, and act as transcription factors to regulate gene expression. Androgen receptor is a member of the nuclear receptor superfamily and is known to be involved in a complex network of signaling pathways that collectively regulate cell proliferation. ${ }^{11,12}$ It is expressed in the normal human mammary gland, where it predominantly localizes to the luminal or inner layer of epithelial cells lining acini and intralobular ducts. ${ }^{13,14}$ The exact role of androgen receptor in normal mammary epithelial biology is unknown. Androgen receptor has been implicated in breast tumorigenesis; however, delineating its precise function has proven difficult, with androgen receptor-mediated androgenic effects shown to both stimulate and inhibit growth of breast cancer cells. ${ }^{15,16}$

The significance of androgen receptor in human breast cancer is further emphasized by the recent finding that it can be targeted in ER-negative breast tumors. ${ }^{17}$ Some studies demonstrated that loss of androgen receptor expression is associated with early-onset, high nuclear-grade, and negative ER, PR and HER2 expression status in breast tumors. ${ }^{18,19}$ However, the mechanisms responsible for this loss of androgen receptor expression in breast carcinogenesis remain unclear. In this study, we investigated the immunohistochemical detection of androgen receptor in a large series of triple-negative breast cancers in our institution and correlated its expression with clinical outcome.

\section{Materials and methods}

\section{Patients and Tumors}

The study cohort comprised 699 triple-negative breast cancers diagnosed at the Department of Pathology, Singapore General Hospital from 1994 to 2010. Clinicopathological parameters including age, ethnicity, tumor size, tubule formation, nuclear pleomorphism, mitotic score, histologic grade, subtype, associated ductal carcinoma in situ, lymphovascular invasion, axillary lymph node status, tumor borders and growth pattern were reviewed.

\section{Tissue Microarray Construction}

Histological slides were retrieved and reviewed. Representative areas were selected and tissue microarrays were constructed using Beecher Microarrayer with $1 \mathrm{~mm}$ cores, two cores per case.

\section{Immunohistochemistry}

Immunohistochemistry was carried out on tissue microarray sections. Antibodies to androgen receptor, CK14, EGFR and $34 \beta$ E12 were applied to sections cut from tissue microarrays. Details of antibodies are shown in Table 1 . Sections $(4 \mu \mathrm{m}$ thick) were cut from tissue microarray blocks and mounted on silanized glass slides and dried on the heating bench for at least $20 \mathrm{~min}$. The sections were deparaffinized in two changes of xylene for $2 \mathrm{~min}$ each. This was followed by rehydration in decreasing concentrations of alcohol from $100 \%$ followed by $95-75 \%$ and finally in water. The rehydrated slides were subjected to heat-induced antigen retrieval using $0.01 \mathrm{M}$ Tris-0.001 M EDTA, pH 9, antigen retrieval solution for $15 \mathrm{~min}$ at sub-boiling temperature of $98^{\circ} \mathrm{C}$ in a microwave (Milestone $\mathrm{T} / \mathrm{T}$ mega). The sections were then stained using the Dako Autostainer Plus according to the following steps. Endogenous peroxidase activity was blocked using hydrogen peroxide (Dako S2022) for $10 \mathrm{~min}$. Slides were incubated with the respective optimized primary antibody for $30 \mathrm{~min}$. The detection system used was Dako Envision Detection kit (K5007), which is a dextran backbone conjugated with secondary antibodies to mouse or rabbit immunoglobulin and horseradish peroxidase. Addition of substrate chromogen, diaminoazobenzidine for 5 min produces an insoluble brown precipitate catalyzed by horseradish peroxidase. Slides were removed from the autostainer and counterstained with Mayer's hematoxylin (Dako S3309). Appropriate controls were run with each batch of slides.

Nuclear staining of androgen receptor, cytoplasmic decoration of CK14 and $34 \beta \mathrm{E} 12$ and cytoplasmic membrane reactivity of EGFR were regarded as a biomarker positivity.

Staining intensity as well as the proportion of tumor cells stained was recorded. The staining was scored separately and the results compared. The finding that yielded the highest scores was used in the analysis. In this study, any unequivocal staining of at least $1 \%$ of tumor cells was regarded as a positive biomarker immunohistochemical expression. ${ }^{20}$ To define basal-like triple-negative breast cancer, we applied a tri-panel of CK14, EGFR and $34 \beta$ E12 with $100 \%$ specificity and $78 \%$ sensitivity as documented in our previous studies. ${ }^{21,22}$

Table 1 Details of antibodies

\begin{tabular}{lllr}
\hline Antibody & Clone & Source & Dilution \\
\hline ER & SP1 & Neomarker RM9101-S & $1: 50$ \\
PR & PgR636 & Neomarker RM9102-S & $1: 200$ \\
C-erbB2 & SP3 & Neomarker RM9103-S & $1: 200$ \\
CK14 & LL002 & NovocastraNCL & $1: 20$ \\
EGFR & E30 & Dako M7239 & $1: 50$ \\
Cytokeratin HMW & 34 $\beta$ E12 & Dako M0630 & $1: 200$ \\
Androgen receptor & AR27 & NCL-AR-318 & $1: 100$ \\
\hline
\end{tabular}




\section{Statistical Analysis}

The findings were analyzed using the statistical software SPSS for Windows, Version 18. The relationship between clinicopathological parameters and immunohistochemical expression of androgen receptor was tested using $\chi^{2}$ and Fisher's exact tests. Follow-up data was obtained from patient case notes. Disease-free survival and overall survival were defined as time from diagnosis to recurrence or death, respectively, and were correlated with immunohistochemical expression of androgen receptor. Survival outcomes were estimated with the Kaplan-Meier analysis and compared between groups with the log-rank statistics. Univariable Cox regression was carried out to evaluate the effect of androgen receptor status on disease-free survival and disease-specific overall survival. As the aim of this study was to compare the disease-free survival and disease-specific overall survival between patients with different androgen receptor status, the effect of androgen receptor was finally adjusted by those significant factors identified by univariable analysis. Hazard ratios together with $95 \%$ confidence intervals were reported for the entire follow-up period, up to 5 years, and from 5 years to the end of follow-up. A $P$-value $<0.05$ defined statistical significance.

\section{Results}

Androgen receptor expression was observed in 267 $(38 \%)$ tumors in our series. The proportion of androgen receptor-positive tumor cells ranged from 1 to $95 \%$ (mean $29 \%$, median 10\%). Of these, about $54 \%$ (144) of tumors harbored androgen receptor immunohistochemical reactivity in $>10 \%$ of tumor cells (Figure 1). The relationship between androgen receptor expression and clinicopathological parameters is shown in Table 2. Androgen receptor positivity was inversely associated with histologic grade $(P=0.002)$ and mitotic score $(P=0.009)$. It was expressed more frequently in tumors with infiltrating borders $(P=0.032)$. No other correlations were observed. In this study, when we used a tri-panel of CK14, EGFR and 34 $\beta$ E12, 593 (85\%) tumors were of basal-like phenotype. Among these, 232 (39\%) tumors showed androgen receptor immunoreactivity. We found that androgen receptor expression was not significantly associated with basal-like triple-negative breast cancer $(P=0.234)$. Among 147 cases with documented metastases in this series, 99 (67\%) primary tumors did not exhibit androgen receptor immunoreactivity. Among 24 tumors with apocrine differentiation in this series, $19(79 \%)$ tumors harbored androgen receptor immunoreactivity $(P<0.001$; Figure 2).

Follow-up ranged from 1 to 213 months (mean 97, median 90). Five- and 10-year overall breast cancer survival rates in androgen receptor-positive

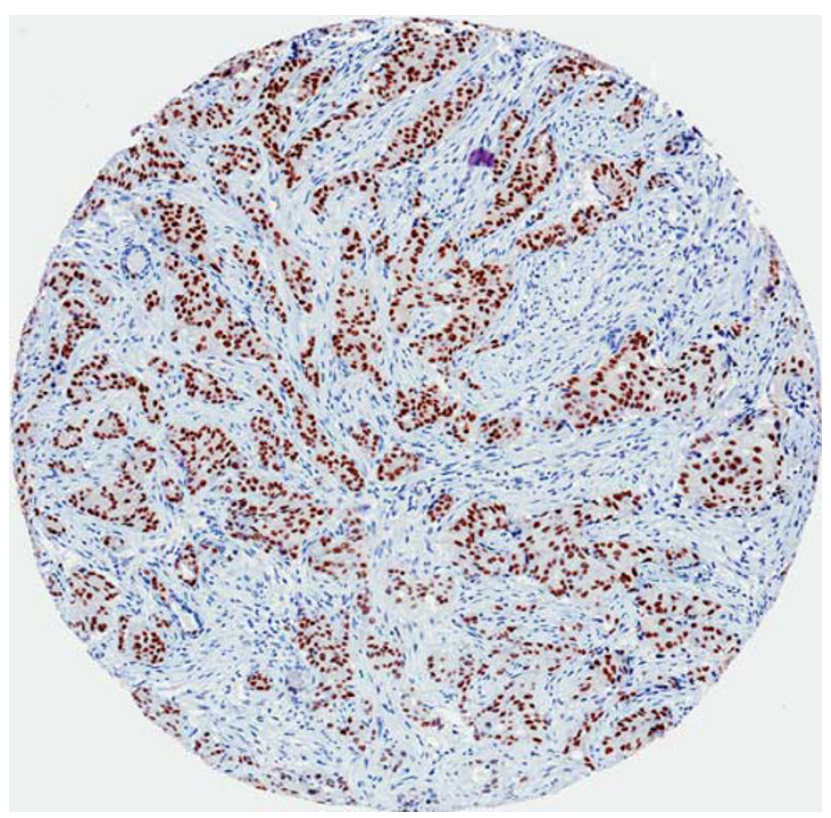

Figure 1 Tissue microarray shows an invasive ductal carcinoma with immunohistochemical nuclear reactivity of tumor cells for androgen receptor.

triple-negative breast cancers were $71 \%$ and $44 \%$, respectively. It was found that women with androgen receptor-positive triple-negative breast cancer had significantly improved disease-free survival and a trend for better overall survival. There was a trend for improved disease-free survival in androgen receptor-positive basal-like triple-negative breast cancers as well, with the overall survival curves appearing to show advantage for androgen receptorexpressing tumors, although the difference was not statistically significant (Figure 3).

Androgen receptor-positive tumors had a decreased likelihood of recurrence in both triple-negative and basal-like phenotype (hazard ratio, 0.704; 95\% confidence intervals: $0.498-0.994 ; P=0.0464$; and hazard ratio, 0.675 ; $95 \%$ confidence intervals: $0.468-0.974$; $P=0.0355$, respectively) within 5 years of diagnosis but not thereafter (Tables 3 and 4).

\section{Discussion}

Androgen receptor expression has been recently examined in several subtypes of breast cancer in patients with clinical follow-up. In these studies, its expression by immunohistochemistry was shown to be associated with a good prognosis in ER/PRnegative cancers. ${ }^{23}$ Conversely, loss of androgen receptor was associated with a poor prognosis in lymph node-positive ER/PR/Her2-negative breast cancers. ${ }^{24}$ These findings are consistent with cellbased assays, where androgen receptor activation with the agonist 5 -dihydrotestosterone ${ }^{25}$ or dehydroepiandrosterone sulfate ${ }^{26}$ inhibits cell growth in androgen receptor-positive breast cancer cell lines, suggesting initiation of a growth inhibitory signal in 
Table 2 Correlation between androgen receptor immunohistochemical detection and clinicopathological parameters $(N=699)$

\begin{tabular}{|c|c|c|c|c|}
\hline Clinicopathological parameters & Total & AR-negative expression & AR-positive expression & $\mathrm{P}$-value \\
\hline Age (years) (mean 53, median 52, range 25-89) & & & & 0.221 \\
\hline$<$ Mean age & 374 & $239(64 \%)$ & $135(36 \%)$ & \\
\hline$\geq$ Mean age & 325 & $193(59 \%)$ & $132(41 \%)$ & \\
\hline Ethnicity & & & & 0.967 \\
\hline Chinese & 583 & $360(62 \%)$ & $223(38 \%)$ & \\
\hline Malay & 58 & $36(62 \%)$ & $22(38 \%)$ & \\
\hline Indian & 37 & $24(65 \%)$ & $13(35 \%)$ & \\
\hline Others & 21 & $12(57 \%)$ & $9(43 \%)$ & \\
\hline Tumor size (mm) (mean 36, median 30, range 9-200) & & & & 0.875 \\
\hline$\leq 20$ & 196 & $120(61 \%)$ & $76(39 \%)$ & \\
\hline$>20$ & 480 & $297(62 \%)$ & $183(38 \%)$ & \\
\hline Histologic grade & & & & $0.002^{\mathrm{a}}$ \\
\hline 1 & 20 & $10(50 \%)$ & $10(50 \%)$ & \\
\hline 2 & 136 & $69(51 \%)$ & $67(49 \%)$ & \\
\hline 3 & 538 & $350(60 \%)$ & $188(40 \%)$ & \\
\hline Tubule formation & & & & 0.072 \\
\hline$>75 \%$ tubule formation & 16 & $10(63 \%)$ & $6(37 \%)$ & \\
\hline$\geq 10-75 \%$ tubule formation & 113 & $59(52 \%)$ & $54(48 \%)$ & \\
\hline$<10 \%$ tubule formation & 570 & $363(64 \%)$ & $207(36 \%)$ & \\
\hline Nuclear pleomorphism & & & & 0.114 \\
\hline Mild & 7 & $3(43 \%)$ & $4(57 \%)$ & \\
\hline Moderate & 219 & $128(58 \%)$ & $91(42 \%)$ & \\
\hline Marked & 473 & $301(64 \%)$ & $172(36 \%)$ & \\
\hline Mitotic score (field diameter $0.5 \mathrm{~mm}$ ) & & & & $0.009^{\mathrm{a}}$ \\
\hline 1 & 58 & $28(48 \%)$ & $30(52 \%)$ & \\
\hline 2 & 154 & $90(58 \%)$ & $64(42 \%)$ & \\
\hline 3 & 481 & $311(65 \%)$ & $170(35 \%)$ & \\
\hline Histologic subtype & & & & 0.611 \\
\hline IDC & 631 & $392(62 \%)$ & $239(38 \%)$ & \\
\hline Non-IDC & 68 & $40(59 \%)$ & $28(41 \%)$ & \\
\hline Associated DCIS & & & & 0.216 \\
\hline Absent & 209 & $136(65 \%)$ & $73(35 \%)$ & \\
\hline Low nuclear grade & 8 & $5(63 \%)$ & $3(37 \%)$ & \\
\hline Intermediate nuclear grade & 70 & $38(54 \%)$ & $32(46 \%)$ & \\
\hline High nuclear grade & 242 & $145(60 \%)$ & $97(40 \%)$ & \\
\hline Lymphovascular invasion & & & & 0.302 \\
\hline Absent & 486 & $295(61 \%)$ & $191(39 \%)$ & \\
\hline Present & 205 & $133(65 \%)$ & $72(35 \%)$ & \\
\hline Axillary lymph node status & & & & 0.936 \\
\hline pNo & 3 & $3(100 \%)$ & $0(0 \%)$ & \\
\hline pN1 & 335 & $211(63 \%)$ & $124(37 \%)$ & \\
\hline pN2 & 140 & $83(59 \%)$ & $57(41 \%)$ & \\
\hline $\mathrm{pN} 3$ & 138 & $89(65 \%)$ & $49(35 \%)$ & \\
\hline Microscopic borders & & & & $0.032^{\mathrm{a}}$ \\
\hline Infiltrating & 589 & $354(60 \%)$ & $235(40 \%)$ & \\
\hline Pushing & 110 & $78(71 \%)$ & $32(29 \%)$ & \\
\hline Growth pattern & & & & 0.436 \\
\hline Trabecular & 322 & $204(63 \%)$ & $118(37 \%)$ & \\
\hline Syncytial & 377 & $228(61 \%)$ & $149(39 \%)$ & \\
\hline Basal-like phenotype & & & & 0.234 \\
\hline No & 106 & $71(67 \%)$ & $35(33 \%)$ & \\
\hline Yes & 593 & $361(61 \%)$ & $232(39 \%)$ & \\
\hline
\end{tabular}

a Statistically significant. 

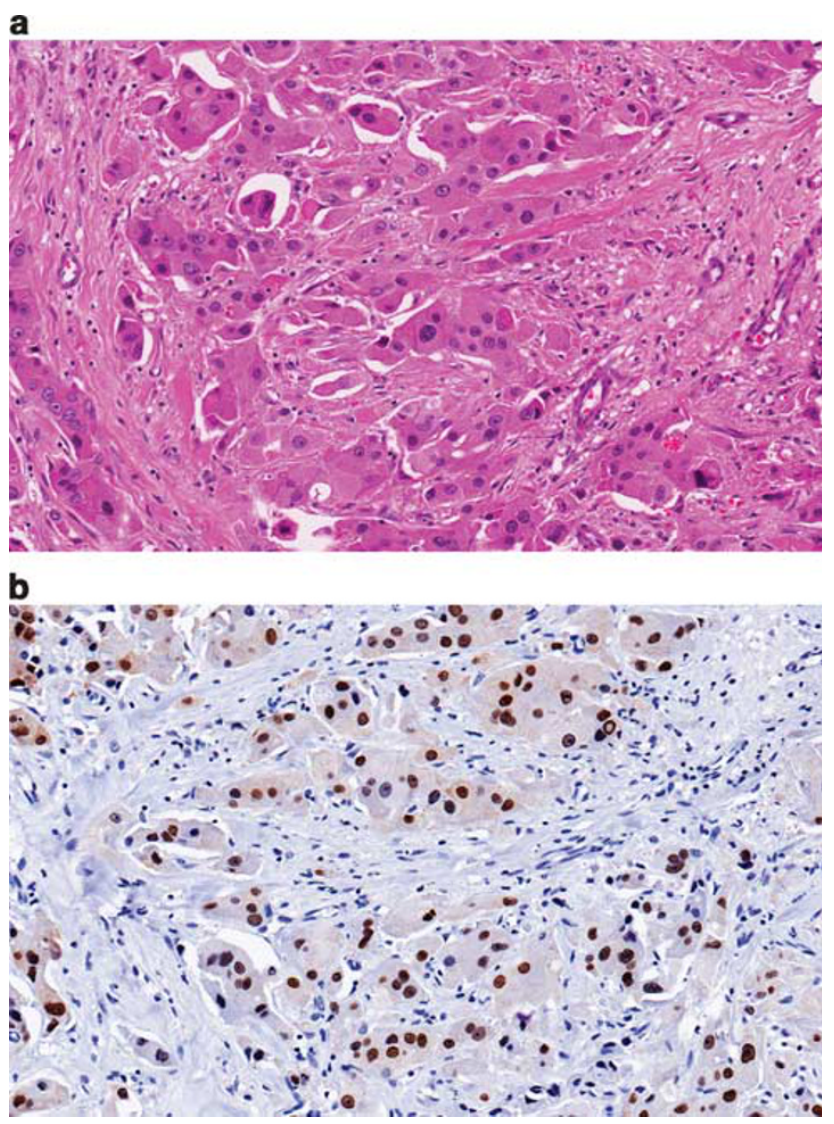

Figure 2 (a) An invasive carcinoma with apocrine cytomorphology. (b) Positive nuclear staining for androgen receptor is observed.

breast cancer. Interestingly, Wilson and co-workers ${ }^{27}$ have found that androgen receptor function can be inhibited by low doses of progestins, which are similar to doses achieved in the serum of women on hormone replacement therapy. Birrell et $a l^{28}$ raised concern that agents such as medroxyprogesterone may negate the protective effects of androgen signaling in the breast.

Androgen receptor expression has been observed in $10-35 \%$ of triple-negative breast carcinomas (Table 5). ${ }^{24,29-31}$ The higher end of this range concurs with the rate of androgen receptor expression of $38 \%$ achieved in our large triple-negative series. Recent studies have found that androgen receptor is expressed in $60-70 \%$ of breast cancers, regardless of ER status. ${ }^{18,29,32}$ It was postulated by Doane et $a l^{15}$ that androgen receptor functions as an antiproliferative effector in ER-positive breast cancer by antagonizing ER, whereas it facilitates tumor cell growth in an androgen-dependent manner in an ER-negative/androgen receptor-positive breast cancer cell line model.

The mechanism by which androgens contribute to breast cancer is not well understood, but some studies have shown that androgens can induce proliferative changes in normal breast tissue. Conversely, androgens have been shown to inhibit the proliferation of androgen receptor-positive breast cancer cell lines, and reduced or impaired androgen receptor signaling has been implicated in the development of hereditary male breast cancers. ${ }^{33-35}$ Park et $a l^{35}$ explained that reduced androgen receptor signaling encourages neoplastic transformation in mammary epithelial cells harboring BRCA1 mutations. They postulated that in women with germline BRCA1 mutations and reduced functional BRCA1 protein, breast epithelial cells are under reduced androgen-mediated growth inhibition and tumors develop more rapidly in those women expressing less efficient androgen receptors.

Other studies have found significant associations between androgen status and worse prognostic factors in keeping with our findings regarding tumor grade and survival outcome. ${ }^{18,19,29,30,32,36,37}$ However, our study could not demonstrate significant association of androgen receptor with age, tumor size, lymph node status or basal-like phenotype. Its frequency of expression in our series is comparable with results of Collins et $a{ }^{38}$ and raises the possibility of targeted therapy to androgen receptor expressing tumors. In our study, disease-free survival was significantly better in androgen receptor-positive-triple negative breast cancer with a trend observed for improved overall survival, as well as a similar trend for better overall survival in androgen receptor-positive basal-like triple-negative breast cancers. Androgen receptor positivity was associated with a decreased likelihood of recurrence in both triple-negative and basal-like phenotype breast cancers within 5 years of diagnosis but not thereafter, suggesting that loss of androgen receptor expression could predict early recurrence in triplenegative breast cancers, including those of basal-like phenotype. In one of the largest studies of androgen receptor status in breast cancer (1371 patients), Bryan and co-workers ${ }^{36}$ found a highly significant association between its status and survival outcome that remained significant even when taking ER status into account. In addition, they found that androgen receptor positivity influenced the response of the primary tumor and metastasis to tamoxifen therapy. The findings in our study are in accord with previous studies as we found that androgen receptor expression was associated significantly with better disease-free survival, with a trend observed for overall survival in triplenegative, and for disease-free survival in tumors with basal-like phenotype. Unlike previous analyses, our study focused on ER-negative tumors and found an association between androgen receptor expression and survival in this subset of patients, who characteristically have a worse prognosis than patients with ER-positive tumors. Based on our findings, we can conclude that loss of androgen receptor expression predicts early recurrence and is of prognostic significance. Whether this difference in disease-free survival is indicative of their more indolent nature or whether it reflects sensitivity to 

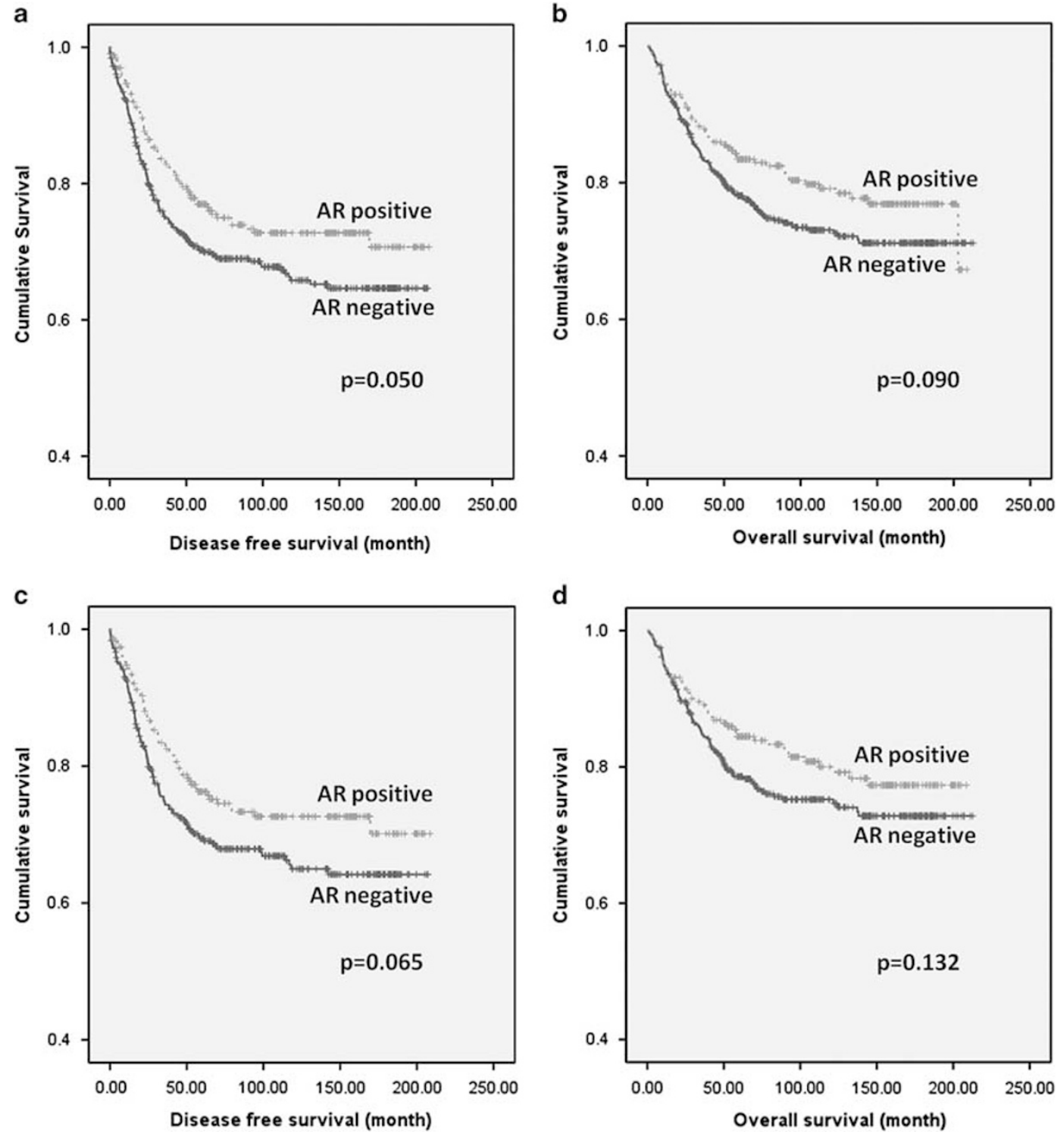

Figure 3 (a) Disease-free survival is improved in androgen receptor-positive triple-negative breast cancer. (b) Overall survival shows a trend for improvement in androgen receptor-expressing triple-negative breast tumors. (c) Disease-free survival in androgen receptorpositive, basal-like triple-negative breast cancer shows a trend for improvement as compared with androgen receptor-negative cases. (d) Although the difference in overall survival between androgen receptor-positive and -negative tumors in basal-like triple-negative breast carcinoma is not statistically significant, the graph displays a more favorable curve for androgen receptor-positive cases.

treatment is unclear, but none of our patients received antiestrogen or antiandrogen therapy.

Our study demonstrates that androgen receptor expression in ER-negative tumors is associated with apocrine differentiation in keeping with the results of Niemeier et al. ${ }^{29}$ Mossler et $a l^{39}$ stated that apocrine carcinomas are deficient in estrogen and progesterone receptors, although they could not find any relationship with either estrogen or progesterone receptor status. ${ }^{39}$ Miller et $a l^{40}$ explained that breast carcinomas showing apocrine differentiation have high $5 \alpha$ reductase activity, which is capable of metabolizing androgens, and possess androgen receptors. These tumors may have a different endocrine drive. The importance of apocrine differentiation in breast carcinomas is uncertain because the incidence of apocrine change is difficult to establish, although extensive apocrine changes are reported in about $4 \%$ of invasive breast carcinomas. ${ }^{41}$ Bundred et $a l^{42}$ found that apocrine differentiation in breast carcinoma is associated with poor prognosis, although they could not explain the reasons for such, and suggested further investigation.

Androgen receptor has biological and therapeutic utilization in prostate cancer, but its use in breast cancer treatment is limited because of the widespread and effective use of antiestrogen hormonal therapies, and dearth of studies comprehensively analyzing its expression in breast cancer. ${ }^{9}$ 
Table 3 Association of immunohistochemical expression of androgen receptor with DFS and disease-specific OS in triple-negative breast cancer $(N=699)$

\begin{tabular}{llll}
\hline Outcome & HR $(95 \%$ CI $)$ & P-value & Adjusted HR (95\% CI $)^{\mathrm{a}}$ \\
\hline DFS & & & \\
$\quad$ Entire follow-up period & $0.748(0.557-1.003)$ & 0.0516 & $0.733(0.533-1.008)$ \\
0-5 years follow-up & $0.782(0.571-1.071)$ & 0.1241 & $0.704(0.498-0.994)$ \\
5 years to end of follow-up & $0.987(0.421-2.311)$ & 0.9760 & $0.970(0.401-2.348)$ \\
OS & & & \\
Entire follow-up period & $0.757(0.548-1.046)$ & 0.0902 & $0.718(0.505-1.022)$ \\
0-5 years follow-up & $0.807(0.561-1.162)$ & 0.2484 & $0.722(0.485-1.076)$ \\
5 years to end of follow-up & $0.857(0.419-1.753)$ & 0.6719 & $0.819(0.385-1.741)$ \\
\hline
\end{tabular}

Abbreviations: DFS, disease-free survival; OS, overall survival.

adjusted by age, size and LN stage.

${ }^{\mathrm{b}}$ Bold indicates statistical significance.

Table 4 Association of immunohistochemical expression of androgen receptor with DFS and disease-specific OS in basal-like triplenegative breast cancer $(N=593)$

\begin{tabular}{|c|c|c|c|c|}
\hline Outcome & $H R(95 \% C I)$ & $\mathrm{P}$-value & Adjusted HR $(95 \% C I)^{\mathrm{a}}$ & $\mathrm{P}$-value \\
\hline \multicolumn{5}{|l|}{ DFS } \\
\hline Entire follow-up period & $0.744(0.543-1.02)$ & 0.0649 & $0.762(0.544-1.069)$ & 0.1153 \\
\hline $0-5$ years follow-up & $0.777(0.556-1.085)$ & 0.1377 & $0.675(0.468-0.974)$ & $0.0355^{b}$ \\
\hline 5 years to end of follow-up & $0.948(0.361-2.493)$ & 0.9139 & $0.950(0.343-2.631)$ & 0.9220 \\
\hline \multicolumn{5}{|l|}{ OS } \\
\hline Entire follow-up period & $0.759(0.530-1.088)$ & 0.1323 & $0.772(0.522-1.140)$ & 0.1924 \\
\hline 0-5 years follow-up & $0.774(0.517-1.161)$ & 0.2142 & $0.706(0.456-1.094)$ & 0.1192 \\
\hline 5 years to end of follow-up & $1.049(0.460-2.393)$ & 0.9088 & $1.088(0.449-2.637)$ & 0.8526 \\
\hline
\end{tabular}

Abbreviations: DFS, disease-free survival; OS, overall survival.

adjusted by age, size and LN stage.

bold indicates statistical significance.

Table 5 Comparison of androgen receptor expression between triple-negative and non-triple-negative breast cancer

\begin{tabular}{|c|c|c|c|}
\hline Authors & Journal & $\begin{array}{c}\text { AR expression in } \\
\text { non-triple-negative breast cancer }\end{array}$ & $\begin{array}{c}\text { AR expression in triple-negative } \\
\text { breast cancer }\end{array}$ \\
\hline Rakha et $a l^{24}$ & Cancer (2007) & $73 \%(1000 / 1370)$ & $13 \%(36 / 282)$ \\
\hline Niemeier et $a l^{29}$ & Mod Pathol (2010) & $93 \%(148 / 159)$ & $10 \%(3 / 30)$ \\
\hline Park et $a l^{30}$ & Ann Oncol (2010) & $80 \%(279 / 350)$ & $35 \%(22 / 63)$ \\
\hline Peters et $a l^{31}$ & Cancer Res (2009) & $83.3 \%(30 / 36)$ & $16.7 \%(3 / 18)$ \\
\hline
\end{tabular}

Abbreviation: AR, androgen receptor.

However, Karamanakos et a ${ }^{43}$ reported that there is a risk of development of breast cancer in prostate cancer patients receiving prolonged antiandrogen monotherapy.

Recent literature has shown that dehydroepiandrosterone and its sulfate have growth inhibitory effects on ER- and PR-negative breast cancer cell lines that show androgen receptor expression. ${ }^{26,44,45}$ These may potentially be applied to ER-negative/ androgen receptor-positive human breast cancers as adjunctive therapy. As aromatase enzyme converts androgens into estrogens, it is thought that if androgens are used in the treatment of ERnegative/androgen receptor-positive tumors, the therapy should be combined with aromatase inhibitors for maximum benefit. ${ }^{44,46}$ Androgen receptor-targeted therapy in combination with chemotherapy in estrogen/progesterone receptornegative tumors may provide an inexpensive alternative to usual high-dose chemotherapy. The findings of our study may allow a better understanding of the role of androgen receptor in the management of triple-negative and basal-like breast cancer.

\section{Conclusion}

Our study demonstrated that loss of androgen receptor expression in triple-negative breast cancer is significantly associated with worse pathological parameters and its expression denoted favorable 
clinical outcomes in both triple-negative and basallike phenotypes. In addition, its absence significantly predicted early recurrence in these tumors. Although the functional role of androgen receptor in breast cancer remains unclear, further exploration of this area could expand the repertoire of potential treatment for patients with triple-negative and basallike breast cancers.

\section{Acknowledgements}

This study was presented in part at the 2013 Annual Meeting of the United States and Canadian Academy of Pathology in Baltimore, MD, USA.

\section{Disclosure/conflict of interest}

The authors declare no conflict of interest.

\section{References}

1 Brenton JD, Carey LA, Ahmed AA, et al. Molecular classification and molecular forecasting of breast cancer: ready for clinical application? J Clin Oncol 2005;23:7350-7360.

2 Nielsen TO, Hsu FD, Jensen K, et al. Immunohistochemical and clinical characterization of the basal-like subtype of invasive breast carcinoma. Clin Cancer Res 2004;10:5367-5374.

3 Dent R, Trudeau M, Pritchard KI, et al. Triple negative breast cancer: clinical features and patterns of recurrence. Clin Cancer Res 2007;13:4429-4434.

4 Rouzier R, Perou CM, Symmans WF, et al. Breast cancer molecular subtypes respond differently to preoperative chemotherapy. Clin Cancer Res 2005;11: 5678-5685.

5 Carey LA, Dees EC, Sawyer L, et al. The triple negative paradox: primary tumor chemosensitivity of breast cancer subtypes. Clin Cancer Res 2007;13:2329-2334.

6 Stagg J, Allard B. Immunotherapeutic approaches in triple-negative breast cancer: latest research and clinical prospect. Ther Adv Med Oncol 2013;5: 169-181.

$7 \mathrm{Yu}$ YL, Chou RH, Liang JH, et al. Targeting the EGFR/ PCNA signaling suppresses tumor growth of triplenegative breast cancer cells with cell-penetrating PCNA peptides. PLoS One 8e61362.

8 Brunello A, Borgato L, Basso U, et al. Targeted approaches to triple negative breast cancer: current practice and future directions. Curr Med Chem 2013; 20:605-612.

9 Moe RE, Anderson BO. Androgens and androgen receptors: a clinically neglected sector in breast cancer biology. J Surg Oncol 2007;95:437-439.

10 Higgins MJ, Wolff AC. The androgen receptor in breast cancer: learning from the past. Breast Cancer Res Treat 2010;124:619-621.

11 Gucalp A, Traina TA. Triple-negative breast cancer: role of the androgen receptor. Cancer J 2010;16:62-65.

12 Yeh S, Hu YC, Wang PH, et al. Abnormal mammary gland development and growth retardation in female mice and MCF7 breast cancer cells lacking androgen receptor. J Exp Med 2003;198:1899-1908.

13 Liao DJ, Dickson RB. Roles of androgens in the development, growth, and carcinogenesis of the mammary gland. J Steroid Biochem Mol Biol 2002; 80:175-189.

$14 \mathrm{Li} \mathrm{S}$, Han B, Liu G, et al. Immunocytochemical localization of sex steroid hormone receptors in normal human mammary gland. J Histochem Cytochem 2010;58:509-515.

15 Doane AS, Danso M, Lal P, et al. An estrogen receptornegative breast cancer subset characterized by a hormonally regulated transcriptional program and response to androgen. Oncogene 2006;25:3994-4008.

16 Birrell SN, Bentel JM, Hickey TE, et al. Androgens induce divergent proliferative responses in human breast cancer cell lines. J Steroid Biochem Mol Biol 1995;52:459-467.

$17 \mathrm{Ni}$ M, Chen Y, Lim E, et al. Targeting androgen receptor in estrogen receptor-negative breast cancer. Cancer Cell 2011;20:119-131.

18 Agoff SN, Swanson PE, Linden H, et al. Androgen receptor expression in estrogen receptor-negative breast cancer. Immunohistochemical, clinical, and prognostic associations. Am J Clin Pathol 2003;120: 725-731.

19 Gonzalez-Angulo AM, Stemke-Hale K, Palla SL, et al. Androgen receptor levels and association with PIK3CA mutations and prognosis in breast cancer. Clin Cancer Res 2009;15:2472-2478.

20 Allred DC, Harvey JM, Berardo M, et al. Prognostic and predictive factors in breast cancer by immunohistochemical analysis. Mod Pathol 1998;11:155-168.

21 Thike AA, Cheok PY, Jara-Lazaro AR, et al. Triplenegative breast cancer: clinicopathological characteristics and relationship with basal-like breast cancer. Mod Pathol 2010;23:123-133.

22 Thike AA, Iqbal J, Cheok PY, et al. Triple negative breast cancer: outcome correlation with immunohistochemical detection of basal markers. Am J Surg Pathol 2010;34:956-964.

23 Kuenen-Boumeester V, Van der Kwast TH, Claassen $\mathrm{CC}$, et al. The clinical significance of androgen receptors in breast cancer and their relation to histological and cell biological parameters. Eur J Cancer 1996;32:1560-1565.

24 Rakha EA, El-Sayed ME, Green AR, et al. Prognostic markers in triple-negative breast cancer. Cancer 2007; 109:25-32.

25 De Launoit Y, Dauvois S, Dufour M, et al. Inhibition of cell cycle kinetics and proliferation by the androgen 5dihydrotestosterone and antiestrogen $\mathrm{N}, n$-butyl- $N$ methyl-11-[16-chloro-3,17-dihydroxy-estra-1,3,5-(10) triene-7yl] undecanamide in human breast cancer ZR-75-1 cells. Cancer Res 1991;51:2797-2802.

26 Hardin C, Pommier R, Calhoun K, et al. A new hormonal therapy for estrogen receptor-negative breast cancer. World J Surg 2007;31:1041-1046.

27 Kemppainen JA, Langley E, Wong CI, et al. Distinguishing androgen receptor agonists and antagonists: distinct mechanisms of activation by medroxyprogesterone acetate and dihydrotestosterone. Mol Endocrinol 1999;13:440-454.

28 Birrell SN, Butler LM, Harris JM, et al. Disruption of androgen receptor signaling by synthetic progestins may increase risk of developing breast cancer. FASEB J 2007;21:2285-2293. 
29 Niemeier LA, Dabbs DJ, Beriwal S, et al. Androgen receptor in breast cancer: expression in estrogen receptor-positive tumors and in estrogen receptornegative tumors with apocrine differentiation. Mod Pathol 2010;23:205-212.

30 Park S, Koo J, Park HS, et al. Expression of androgen receptors in primary breast cancer. Ann Oncol 2010; 21:488-492.

31 Peters AA, Buchanan G, Ricciardelli C, et al. Androgen receptor inhibits estrogen receptor-alpha activity and is prognostic in breast cancer. Cancer Res 2009;69: 6131-6140.

32 Kuenen-Boumeester V, Van der Kwast TH, Claassen CC, et al. The clinical significance of androgen receptors in breast cancer and their relation to histological and cell biological parameters. Eur J Cancer 1999;32:1560-1565.

33 Wong YC, Xie B. The role of androgens in mammary carcinogenesis. Ital J Anat Embryol 2001;106:111-125.

34 Xie B, Tsao SW, Wong YC. Sex hormone-induced mammary carcinogenesis in female noble rats: the role of androgens. Carcinogenesis 1999;20:1597-1606.

35 Park JJ, Irvine RA, Buchanan G, et al. Breast cancer susceptibility gene 1 (BRCAI) is a coactivator of the androgen receptor. Cancer Res 2000;60:5946-5949.

36 Bryan RM, Mercer RJ, Bennett RC, et al. Androgen receptors in breast cancer. Cancer 1984;54:2436-2440.

37 Isola JJ. Immunohistochemical demonstration of androgen receptor in breast cancer and its relationship to other prognostic factors. J Pathol 1993;170:31-35.

38 Collins LC, Cole KS, Marotti JD, et al. Androgen receptor expression in breast cancer in relation to molecular phenotype: results from the Nurses' Health Study. Mod Pathol 2011;24:924-931.

39 Mossler JA, Barton TK, Brinkhous AD, et al. Apocrine differentiation in human mammary carcinoma. Cancer 1980;46:2463-2471.

40 Miller WR, Shivas AA, Franchimont P, et al. Breast gross cystic disease protein 15 in human breast cancer in culture. Eur J Cancer Clin Oncol 1988;24: $223-228$

41 O’Malley F, Eusebi V, Lakhani SR. Carcinomas with apocrine differentiation; In: Ellis IO, Schnitt SJ, Tan $\mathrm{PH}$, van de Vijver MJ (eds)., WHO Classification of Tumours of the Breast 4th edn. IARC Press: Lyon, France; 2012, pp 53-54.

42 Bundred NJ, Walker RA, Everington D, et al. Is apocrine differentiation in breast carcinoma of prognostic significance? Br J Cancer 1990;62:113-117.

43 Karamanakos P, Mitsiades CS, Lembessis P, et al. Male breast adenocarcinoma in a prostate cancer patient following prolonged anti-androgen monotherapy. Anticancer Res 2004;24:1077-1081.

44 Nahleh Z. Androgen receptor as a target for the treatment of hormone receptor-negative breast cancer: an unchartered territory. Fut Oncol 2008;4: $15-21$.

45 Toth-Fejel S, Cheek J, Calhoun K, et al. Estrogen and androgen receptors as comediators of breast cancer cell proliferation: providing a new therapeutic tool. Arch Surg 2004;139:50-54.

46 Suzuki T, Miki Y, Akahira J, et al. Aromatase in human breast carcinoma as a key regulator of intratumoral sex steroid concentrations. Endocr J 2008;55:455-463. 